\title{
Substrate Profiling of Protein Tyrosine Phosphatase PTP1B by Screening a Combinatorial Peptide Library
}

\section{(Supporting Information)}

\author{
Mathieu Garaud and Dehua Pei*
}

\begin{abstract}
Materials. Tyrosinase from mushroom (T3824), (+)-biotin hydrazide (B7639), 5-bromo4-chloro-3-indolyl phosphate (BCIP), 4-hydroxy-R-cyanocinnamic acid, and organic solvents were obtained from Sigma-Aldrich. Stock solutions of biotin hydrazide were prepared in a minimal volume of DMSO. Streptavidin-alkaline phosphatase (SA-AP) was from Prozyme. Reagents for peptide synthesis were from Advanced ChemTech, Peptides International, and NovaBiochem. N-(9-Fluorenylmethoxycarbonyloxy)succinimide (Fmoc-OSU) was from Advanced ChemTech. Phenyl isothiocyanate was purchased in 1-mL sealed ampoules from Sigma-Aldrich and used without purification. Protein concentration was determined by the Bradford method using bovine serum albumin (Sigma-Aldrich) as standard. PTP1B was overexpressed in E. coli and purified as previously described. ${ }^{[1]}$
\end{abstract}

Buffers. Buffer A, $30 \mathrm{mM}$ Hepes ( $\mathrm{pH} 7.4$ ), $150 \mathrm{mM} \mathrm{NaCl}, 0.01 \%$ Tween $20,0.1 \%$ gelatin; buffer B, $50 \mathrm{mM}$ Hepes ( $\mathrm{pH} 7.4$ ), $150 \mathrm{mM} \mathrm{NaCl}, 10 \mathrm{mM} \mathrm{MgCl} 2,0.01 \%$ Tween 20,1 $\mathrm{mM}$ tris(carboxyethyl)phosphine (TCEP); buffer $\mathrm{C}, 0.1 \mathrm{M} \mathrm{KH}_{2} \mathrm{PO}_{4}(\mathrm{pH} 7.2)$ filtered through a $0.45 \mu \mathrm{M}$ Acrodisc syringe filter (Life Sciences); buffer D, $30 \mathrm{mM}$ Tris (pH 7.4), $10 \mathrm{mM} \mathrm{MgCl}_{2}$, $250 \mathrm{mM} \mathrm{NaCl}$; buffer E, $30 \mathrm{mM}$ Tris ( $\mathrm{pH} 8.5$ ), $5 \mathrm{mM} \mathrm{MgCl} 2,0.02 \mathrm{mM} \mathrm{ZnCl} 2,100 \mathrm{mM} \mathrm{NaCl}$; and buffer F, $100 \mathrm{mM}$ Hepes (pH 7.4), 100 mM NaCl, 2 mM EDTA, 5 mM TCEP.

Peptide Library Synthesis. Library A [Fmoc-XXXXXpYAALNBBRM-resin, where X is norleucine (Nle) or any of the 17 proteinogenic amino acids except for Met, Cys, and Tyr] was synthesized on $2 \mathrm{~g}$ of $90-\mu \mathrm{m}$ TentaGel $\mathrm{S} \mathrm{NH} \mathrm{N}_{2}$ resin using standard Fmoc/HBTU/HOBt/DIPEA chemistry. The invariant positions (pYAABBRM) were synthesized with 4 equivalents of Fmocamino acids, and the coupling reaction was terminated after ninhydrin tests were negative. The random positions were synthesized using the split-synthesis method. ${ }^{[2]}$ Each coupling reaction employed 5 equivalents of Fmoc-amino acids and was allowed to proceed for 60 min, after which the coupling reaction was repeated once to ensure complete reaction. To facilitate sequence determination by mass spectrometry, $5 \%(\mathrm{~mol} / \mathrm{mol}) \mathrm{CD}_{3} \mathrm{CO}_{2} \mathrm{D}$ was added to the coupling reactions of leucine and lysine, whereas $5 \% \mathrm{CH}_{3} \mathrm{CD}_{2} \mathrm{CO}_{2} \mathrm{D}$ was added to the coupling reaction of Nle. ${ }^{[3]}$ The resin-bound library containing the N-terminal Fmoc group was washed with dichloromethane and side-chain deprotected using a modified reagent $\mathrm{K}$ [7.5\% phenol, 5\% water, $5 \%$ thioanisole, $2.5 \%$ ethanedithiol and $1 \%$ anisole in trifluoroacetic acid (TFA)] at room temperature for $60 \mathrm{~min}$. The library was washed with TFA and dichloromethane, dried in vacuo, and stored at $-20{ }^{\circ} \mathrm{C}$. Library B (TAXXpYXXXLNBBRM-resin) was synthesized as previously described, ${ }^{[4]}$ in which $\mathrm{X}$ represents 18 proteinogenic amino acids except for cysteine [which is replaced by aminobutyric acid (Abu)] and methionine (which is replaced by Nle). Library $\mathrm{C}$ (YXXXXXYBBRM-resin, where $\mathrm{X}$ is Nle or any of the 18 proteinogenic amino acids except for Cys ad Met) was similarly synthesized. 
Derivatization of Tyrosine-Containing Peptides by Biotin Hydrazide. A tyrosinecontaining peptide (RALYDNVPE) (final concentration $200 \mu \mathrm{M}$ ) and biotin hydrazide (final concentration $20 \mathrm{mM}$ ) were dissolved in $0.1 \mathrm{~mL}$ of buffer C. Tyrosinase from mushroom (final concentration $0.5 \mu \mathrm{M}$ ) was added to the solution and the reaction volume was adjusted to $1 \mathrm{~mL}$ by the addition of buffer $\mathrm{C}$. The mixture was incubated at $4{ }^{\circ} \mathrm{C}$ overnight with gentle mixing and filtered through a $\mathrm{C}_{18}$ cartridge (Burdick and Jackson $\mathrm{B} \alpha \mathrm{J}$ solid phase System columns) to remove the protein. The resulting solution was analyzed by reversed-phase HPLC on a $\mathrm{C}_{18}$ column (Vydac $300 \AA, 4.6 \times 250 \mathrm{~mm}$ ). The column was eluted with a linear of gradient of $10-60 \%$ acetonitrile in water containing $0.05 \%$ TFA (flow rate $1.0 \mathrm{~mL} / \mathrm{min}$ ). The eluted peptides were analyzed by MALDI-TOF mass spectrometry. One microliter of the peptide solution was mixed with $2 \mu \mathrm{L}$ of a saturated solution of 4-hydroxy- $\alpha$-cyanocinnamic acid in $50 \%$ acetonitrile containing $0.1 \%$ TFA and $1 \mu \mathrm{L}$ of the sample was spotted onto a $96-$ well sample plate. Mass spectrometry was performed on a Bruker Reflex III MALDI-TOF instrument in an automated manner. A control experiment without tyrosinase was carried out under the same condition.

The untreated peptide (no tyrosinase) had a retention time $\left(\mathrm{T}_{\mathrm{R}}\right)$ of $18.8 \mathrm{~min}$ on HPLC (Figure S1 panel $a$ ) and a molecular mass of 1075.3 Da (Figure S2 panel $a$ ). After the treatment with tyrosinase and biotin hydrazide, the 18.8-min peak completely disappeared and a new peak appeared at 16.5 min (Figure S1 panel $b$ ). Co-injection of the starting material and the reaction product shows that the two species have distinct retention times (Figure S1 panel $c$ ). MS analysis revealed that the reaction product had a molecular mass of $1350.2 \mathrm{Da}$, an increase of molecular mass by 275.0 amu (Figure S2 panel $b$ and $c$ ). Similar experiments with peptides biotinminiPEG-MAPpYDNYVP $\left(\mathrm{m} / \mathrm{z}=1557.3\right.$ for $\left[\mathrm{M}+\mathrm{K}^{+}\right]$) (Figure S3) and formyl-FYFSBBRM $\left(\mathrm{m} / \mathrm{z}=1018.9\right.$ for $\left.\left[\mathrm{M}+\mathrm{H}^{+}\right]\right)$(data not shown) showed an increase of molecular mass by 272.0 amu after derivatization. These results are consistent with the addition of a single biotin hydrazide molecule to the tyrosine side chain. As a control, a pY peptide (NNIQpYALCLNR) was subjected to the same treatment (tyrosinase and biotin hydrazide) and analyzed by HPLC and MS. The pY peptide was not modified by the procedure.

Library Screening against Tyrosinase. In a micro-BioSpin column ( $0.8 \mathrm{~mL}$, Bio-Rad), $10 \mathrm{mg}$ of library B ( 28,600 beads) was swollen in dichloromethane, washed extensively with DMF, $\mathrm{ddH}_{2} \mathrm{O}$, and buffer $\mathrm{A}$, and then blocked for $1 \mathrm{~h}$ with $800 \mu \mathrm{L}$ of buffer $\mathrm{A}$. The resin was drained and resuspended in $800 \mu \mathrm{L}$ of buffer $\mathrm{C}$ containing tyrosinase $(10 \mu \mathrm{M}$ final concentration). This solution was transferred into a microcentrifuge tube and incubated overnight at $4{ }^{\circ} \mathrm{C}$, with exposure to air and gentle mixing. The resin was then drained, transferred back into the micro-BioSpin column, and resuspended in $800 \mu \mathrm{L}$ of buffer $\mathrm{C}$ containing biotin hydrazide (100 $\mu \mathrm{M}$ final concentration). The solution was incubated for $4 \mathrm{~h}$ at $4{ }^{\circ} \mathrm{C}$ with gentle mixing. The resin was drained and resuspended in $800 \mu \mathrm{L}$ of buffer D containing $1 \mu \mathrm{L}$ of streptavidinalkaline phosphatase (Prozyme, $1 \mathrm{mg} / \mathrm{mL}$ ). After 20 min of gentle mixing at $4{ }^{\circ} \mathrm{C}$, the resin was drained and washed with $800 \mu \mathrm{L}$ of buffer D, $800 \mu \mathrm{L}$ of buffer A, and $800 \mu \mathrm{L}$ buffer E. The resin was then transferred to a 35-mm Petri dish by rinsing with $5 \times 300 \mu \mathrm{L}$ of buffer $\mathrm{E}$ and 100 $\mu \mathrm{L}$ of $5 \mathrm{mg} / \mathrm{mL}$ BCIP in buffer $\mathrm{E}$ was added. The resulting mixture was incubated at room temperature and intense turquoise color developed on positive beads in $\sim 90 \mathrm{~min}$, when the staining reaction was quenched by the addition of $3 \mathrm{~mL}$ of $1 \mathrm{M} \mathrm{HCl}$. The resin was transferred back into the BioSpin column, extensively washed with water, and transferred to a Petri dish, from which colored beads were manually picked with the aid of a dissecting microscope. 
The above procedure resulted in turquoise color on $\sim 20 \%$ of the beads. Twenty colored and 20 colorless beads were randomly picked from the library and their peptide sequences were determined by partial Edman degradation/mass spectrometry (PED/MS). ${ }^{[3]}$ Table S1 lists the sequences of the 20 colored beads, each of which contained at least one tyrosine in the sequence. In contrast, none of the 20 colorless beads had any tyrosine in their sequences (Table S2). These results demonstrate that treatment with tyrosinase and biotin hydrazide selectively modifies tyrosine residues in peptides, but not the pY or any other residues.

To test whether tyrosinase accepts all Tyr-containing peptides as substrates, $1 \mathrm{mg}$ of library $\mathrm{C}$ (which contains two fixed Tyr residues $\mathrm{N}$ - and $\mathrm{C}$-terminal to the random region) was subjected to the same screening procedure as described above. All of the library beads $(\sim 2800$ beads) became turquoise colored, although some beads developed color faster than others and the final color intensities were not uniform (a photograph of a small fraction of the stained beads is shown in Figure S7). This result indicates that tyrosinase accepts any Tyr-containing peptides as substrates, consistent with the previous observation that simple phenol and phenol derivatives are excellent substrates of mushroom tyrosinase. ${ }^{[5]}$ The faster color-developing beads most likely contained additional Tyr in the random sequence region. It is also possible that tyrosinase have higher activity toward certain peptide sequences.

Library Screening Against PTP1B. Screening of library A against PTP1B was carried out in a similar manner but with the following modifications. A typical screening involved $50 \mathrm{mg}$ of the library, which was swollen in dichloromethane, washed extensively with $\mathrm{DMF}, \mathrm{ddH}_{2} \mathrm{O}$, and buffer $\mathrm{A}$, and then blocked for $1 \mathrm{~h}$ with $800 \mu \mathrm{L}$ of buffer $\mathrm{A}$. The resin was drained and resuspended in $800 \mu \mathrm{L}$ of buffer B containing PTP1B (1 $\mu \mathrm{M}$ final concentration). After incubation at $4{ }^{\circ} \mathrm{C}$ for $6 \mathrm{~h}$, the resin was drained, washed with buffer $\mathrm{C}$, and treated with tyrosinase $(10 \mu \mathrm{M}$ final concentration) and biotin hydrazide (100 $\mu \mathrm{M}$ final concentration) in buffer $\mathrm{C}$ for $6 \mathrm{~h}$ at $4{ }^{\circ} \mathrm{C}$, followed by on-bead colorimetric assay as described above. A control experiment without PTP1B was performed and produced no colored beads under otherwise identical conditions.

The screening procedure was carried out three times, each with $50 \mathrm{mg}$ library A. The most intensely colored beads were picked from the libraries and their sequences are listed in Tables S3-5. Fifty intermediately colored and 50 lightly colored beads were randomly selected from the third screening experiment. Their sequences are listed in Tables S6 and S7, respectively. A plot of these sequences shows that PTP1B can accept a wide variety of sequences as substrates but has a general preference for acidic residues $(\sim 65 \%$ of the selected peptides contained at least one acidic residue, Asp or Glu, N-terminal to pY) (Figure S4).

To identify peptides that are resistant to PTP1B reaction, $10 \mathrm{mg}$ of library A was suspended in buffer B and treated with an increased concentration of PTP1B (20 $\mu \mathrm{M}$ final) for 6 $\mathrm{h}$ at $4{ }^{\circ} \mathrm{C}$. The solution was drained and the PTP1B treatment was repeated once. After that, the beads were washed and treated with tyrosinase $(20 \mu \mathrm{M}$ final concentration) in the presence of $100 \mu \mathrm{M}$ biotin hydrazide (for $6 \mathrm{~h}$ at $4{ }^{\circ} \mathrm{C}$ ), followed by on-bead colorimetric assay as described above. This screening resulted in $\sim 60 \%$ colored beads. Fifty colorless beads were randomly selected from the library and their sequences were determined (Table S8). These poor substrates showed a general lack of acidic residues N-terminal to pY (Figure S5). 
Synthesis of Individual pY Peptides. Individual peptides were synthesized on $100 \mathrm{mg}$ of CLEAR-amide resin using standard Fmoc/HBTU/HOBt chemistry. Cleavage and deprotection were carried out using reagent $\mathrm{K}$ as described above. After evaporation of solvents, the mixture was triturated twice with 20 volumes of $\mathrm{Et}_{2} \mathrm{O}$. The precipitate was collected and dried under vacuum. The crude peptides were purified by reversed-phase HPLC on a $\mathrm{C}_{18}$ column. The identity of each peptide was confirmed by MALDI-TOF mass spectrometric analysis.

PTP Assay. PTP assays were performed with the synthetic pY peptides as substrates in a quartz microcuvette. A typical reaction (total volume $100 \mu \mathrm{L}$ ) contained buffer $\mathrm{F}$ and $0-200 \mu \mathrm{M}$ pY peptide. The reaction was initiated by the addition of $7 \mu \mathrm{L}$ of a PTP1B stock solution (final concentration $5 \mathrm{nM}-10 \mu \mathrm{M})$ and monitored continuously at $282 \mathrm{~nm}\left(\Delta \varepsilon=1102 \mathrm{M}^{-1} \mathrm{~cm}^{-1}\right)$ on a UV-VIS spectrophotometer. The initial rates were calculated from the early regions of the curves $(<30 \mathrm{~s})$ and fitted to the Michaelis-Menten equation to obtain the $k_{\text {cat }}, K_{\mathrm{M}}$ and $k_{\mathrm{cat}} / K_{\mathrm{M}}$ values for each peptide. Figure $\mathrm{S} 6$ shows the $\mathrm{V}$ vs [S] plots of peptide RTINEpYAA- $\mathrm{NH}_{2}$ as an example (from three independent experiments).

[1] Park, J.; Pei, D. Biochemistry 2004, 43, 15014.

[2] (a) Lam, K. S.; Salmon, S. E.; Hersh, E. M.; Hruby, V. J.; Kazmierski, W. M.; Knapp, R. J. Nature 1991, 354, 82. (b) Houghten, R. A.; Pinilla, C.; Blondelle, S. E.; Appel, J. R.; Dooley, C. T.; Cuervo, J. H. Nature 1991, 354, 84.

[3] Thakkar, A.; Wavreille, A.-S.; Pei, D. Anal. Chem. 2006, 78, 5935.

[4] Sweeney, M.; Wavreille, A.; Park, J.; Butchar, J.; Tridandapani, S.; Pei, D. Biochemistry 2005, 44, 14932.

[5] Espin, J. C.; Varon, R.; Fenoll, L. G.; Gilabert, M. A.; Garcia-Ruiz, P. A.; Tudela, J.; GarciaCanovas, F. Eur. J. Biochem. 2000, 267, 1270.

\begin{tabular}{|c|c|}
\hline \multicolumn{2}{|c|}{ Table S1: Sequences of 20 colored } \\
beads from library B (modified by \\
\multicolumn{2}{|c|}{ tyrosinase and biotin hydrazide) } \\
\hline KKpYYRY & AYpYRTM \\
KYpYRMY & KSpYRYL \\
YLpYRYR & WYpYVRH \\
YSpYRRR & RNpYAYC \\
YRpYYRR & KRPYYNC \\
YRpYYYK & YKpYRSF \\
LTpYRYC & VYPYTIP \\
KRPYCYC & PYPYRLR \\
YApYSMC & VYPYTPT \\
YGPYHKS & YPPYRTP \\
\hline
\end{tabular}

${ }^{a}$ Key: C, 2-aminobutyrate; M, norleucine.

\begin{tabular}{|c|c|}
\hline \multicolumn{2}{|c|}{$\begin{array}{l}\text { Table S2: Sequences of } 20 \text { colorless } \\
\text { beads from library B (not modified by } \\
\text { tyrosinase and biotin hydrazide) })^{a}\end{array}$} \\
\hline PFpYGLQ & PFPYALR \\
\hline TVPYFAL & LDPYEIL \\
\hline QTpYRDS & HSPYPCK \\
\hline AGpYFIV & VLPYPSL \\
\hline PApYGFT & VTPYIHK \\
\hline PFpYDQI & FVpYKLD \\
\hline TMpYSFL & CFPYTWM \\
\hline PPpYAEF & VPpYALV \\
\hline PLPYPIL & PFPYHVI \\
\hline FQPYSCA & RGpYSML \\
\hline
\end{tabular}

${ }^{a}$ Key: C, 2-aminobutyrate; M, norleucine. 
Table S3. Sequences of the 12 most intensely colored beads from library A screened against PTP1B $\left(1^{\text {st }} \text { screening experiment }\right)^{a}$

\begin{tabular}{c|c|c}
\hline KAVFI* & RTIEW* & MGDEQ \\
KALHG & VPGEW & QEDEP* \\
KAIFL & TMHEW & DRRVA \\
KSVEN & & \\
RAMLM & & \\
RTINE* & & \\
\hline
\end{tabular}

${ }^{a}$ Key: M, norleucine; ${ }^{*}$, sequences that were selected for individual synthesis and kinetic analysis.

Table S4. Sequences of the 46 most intensely colored beads from library A screened against PTP1B (2nd screening experiment) ${ }^{a}$

\begin{tabular}{|l|l|l|l|l|}
\hline KAIHQ & KSIVS & RGIAS & AGFEW & SEDEW \\
KAITQ & KSVDK & RGLNR & GHGEW & QGPEW \\
KALGF & KSVKT & RGVSE & LHGEW & LPREW \\
KALKI & KTINV & RGVVE & GDHEW & HWSEW \\
KAVGI & RAINP & RTLGV & SNHEW & QGSEW \\
KAVQS & RALIF & RTVNA & HLKEW & ELWEW \\
KGLKE & RALRF & & HWLEW & \\
KGLLR & RALFI & RHAEW & AANEW & ETHVV \\
KGLET & RALQS & SHAEW & PSNEW & \\
KGLQT & RAVDF & NWDEW & HHPEW & \\
\hline
\end{tabular}

${ }^{a}$ Key: M, norleucine

Table S5. Sequences of the 25 most intensely colored beads from library A screened against PTP1B (3rd screening experiment) ${ }^{a}$

\begin{tabular}{|l|l|l|l|}
\hline KALSV & RALVS & DEAEW & QWREW \\
KGIFE & RGIII & EKDEW & KGSEW \\
KGIEG & RGLIF & AAGEW & QWWEW \\
KTVDR & RGVDE & LNGEW & \\
RAIDT & RSIDD & DSHEW & DDTWD \\
RALRI & RSLKQ & FKNEW & EHDDA \\
RALIQ & & FHPEW & \\
\hline
\end{tabular}

${ }^{a}$ Key: M, norleucine 
Table S6. Sequences of 50 randomly selected intermediately colored beads from library A screened against PTP1B (total 40 complete sequences) ${ }^{a}$

\begin{tabular}{l|l|l|l|l|} 
TNNAQ & QSMEV & FADHI & HADMQ & TVDSA \\
KQGAS & HGNEW & INEHN & FNTPQ & GLESK \\
IALDA & TAEFS & EDHDI & PLAQE & DTDTI \\
VHWDE & EHTGH* & VHFIK & ETDQF & KKRTQ \\
WFIDN & MALGQ & FEQIN & NFHQF & EGGVI \\
MRLEF & PRNEH & TLQLD & SELQR & QVHHS \\
WLAEG & QIMHF & AFFNE & FWWSQ & RSMWI \\
IAPES & STKHH & RGQNS & IGFRP & MVDWQ \\
\hline
\end{tabular}

${ }^{a}$ Key: M, norleucine; *, sequence selected for individual synthesis and kinetic analysis.

Table S7. Sequences of 50 randomly selected lightly colored beads from library A screened against PTP1B (total 45 complete sequences) ${ }^{a}$

\begin{tabular}{|c|c|c|c|c|}
\hline PMDND & GVGKV & NQGMD & KDRSH & NNNKN \\
\hline KSEND & TIWEH & RDLHI & DHVTQ* & REWEF \\
\hline AMNQP & VTRDP & EMDEF & DHSIG & FMHVS \\
\hline VDWWK & NIHAP & MFLSN & QLIRD & FMINM \\
\hline VDDAM & SNFLR & LAFAH & DFPEI & WESVF \\
\hline ADANN & WTWNG & QDPGA & HREFV & ADTWP \\
\hline DDVSF & ESPGL & VEDHR & PERWQ & VMLMH \\
\hline HPAPD & QSEDF & VNQPL & MLHVD & TLNQI \\
\hline DMLNI & VFHRG & EVREI & ARRKN & QMIGH \\
\hline
\end{tabular}

${ }^{a}$ Key: M, norleucine; *, sequence selected for individual synthesis and kinetic analysis.

Table S8. Sequences of 50 randomly selected colorless beads from library A screened against PTP1B (total 44 complete sequences) ${ }^{a}$

\begin{tabular}{|l|l|l|l|}
\hline HNTIA & AGMAK & IAQPP & VWSWQ \\
LLIRF & ALARL & FFNHP & FGPHR \\
AIAKG & THIQN & WGSGP & VNQRR \\
NLQWG & NLNLN & WHKQP & APVAR \\
ANFPG & LRRHN & NNWTP & RPWES \\
PPSHG & FVAMN & TDFQQ & PQMQS \\
LKMRH & AAAIM & AGQDQ & VWHTS \\
NTNPH & DAVHM & LGAIQ & NHILT \\
WVWLH & SAKHM & SKTQQ & KRTST \\
NPDII & FSRKM & RLKQQ* & NARNV \\
HRQNI & ITNIM & KWAWQ & LQGWV \\
\hline
\end{tabular}

${ }^{a}$ Key: M, norleucine; *, sequence selected for individual synthesis and kinetic analysis. 

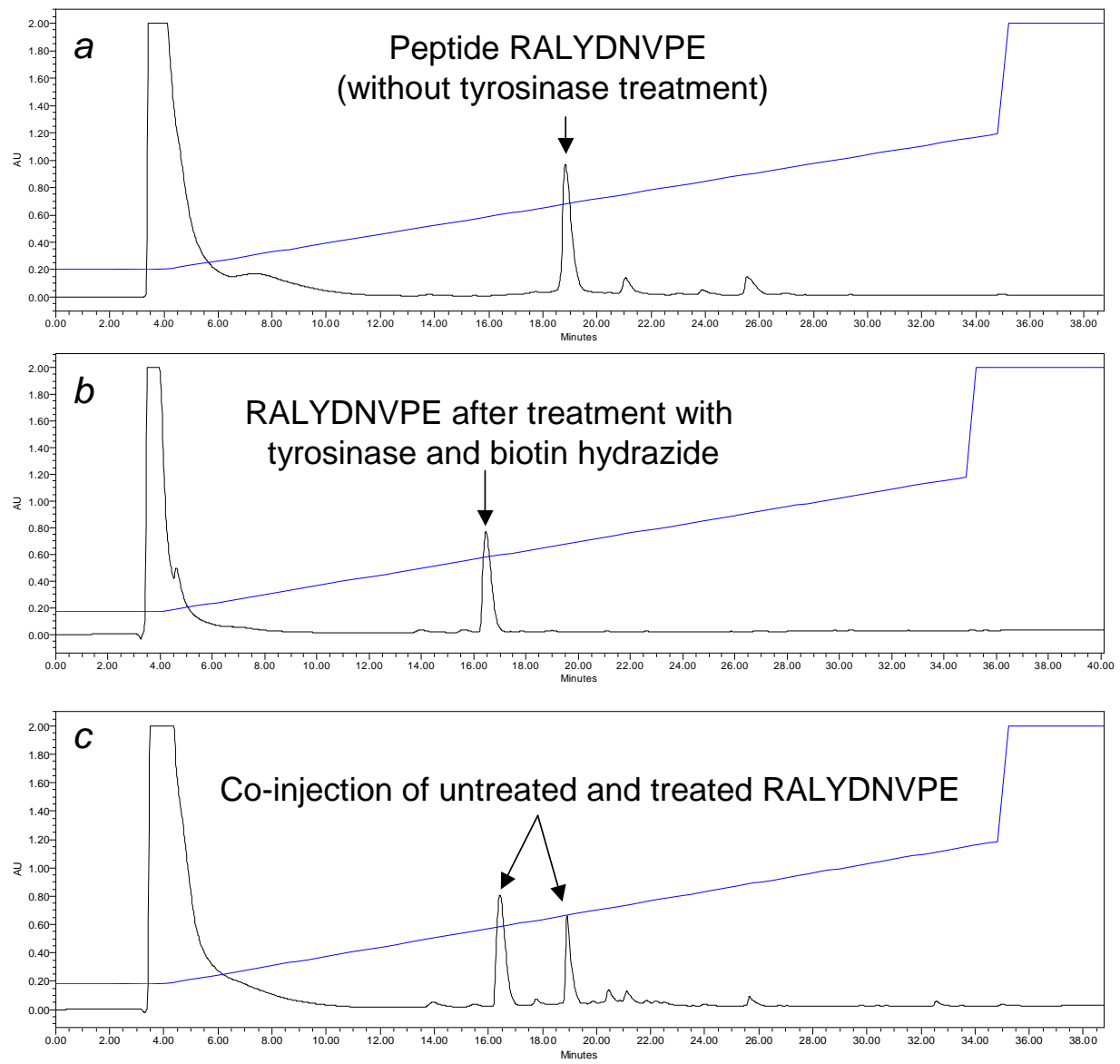

Figure S1. HPLC chromatograms of untreated peptide RALYDNVPE (a), the peptide after tyrosinase and biotin hydrazide treatment $(\boldsymbol{b})$, and the co-injection of the untreated and treated peptides (c). 

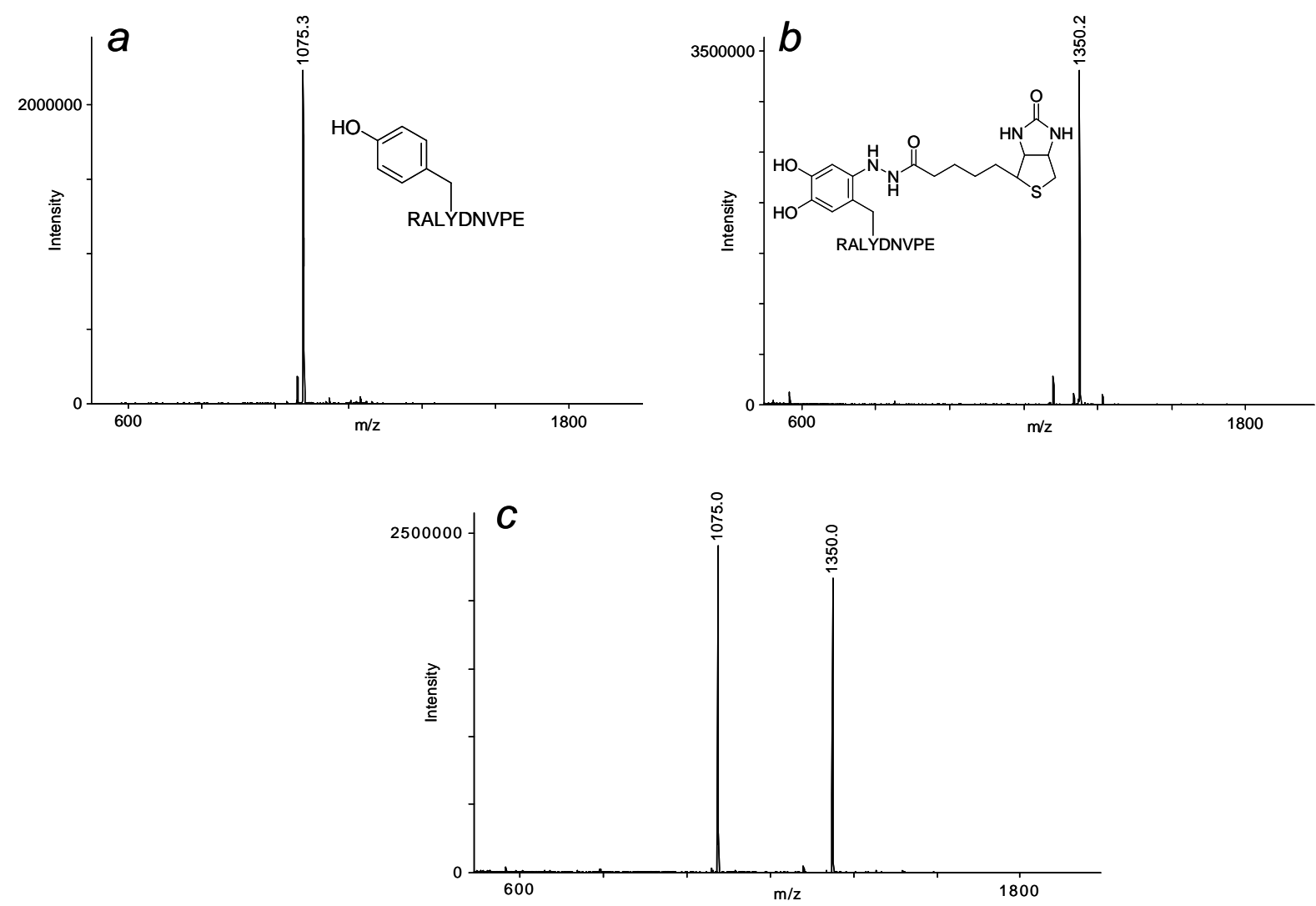

Figure S2. (a) MALDI-TOF mass spectrum of untreated peptide RALYDNVPE (the peak with $\mathrm{T}_{\mathrm{R}}=18.8 \mathrm{~min}$ in Figure S1a); (b) mass spectrum of the peptide after treatment with tyrosinase and biotin hydrazide (peak with $\mathrm{T}_{\mathrm{R}}=16.5 \mathrm{~min}$ in Figure $\mathrm{S} 1 \mathrm{~b}$ ); (c) mass spectrum of a mixture of the untreated and treated peptides.
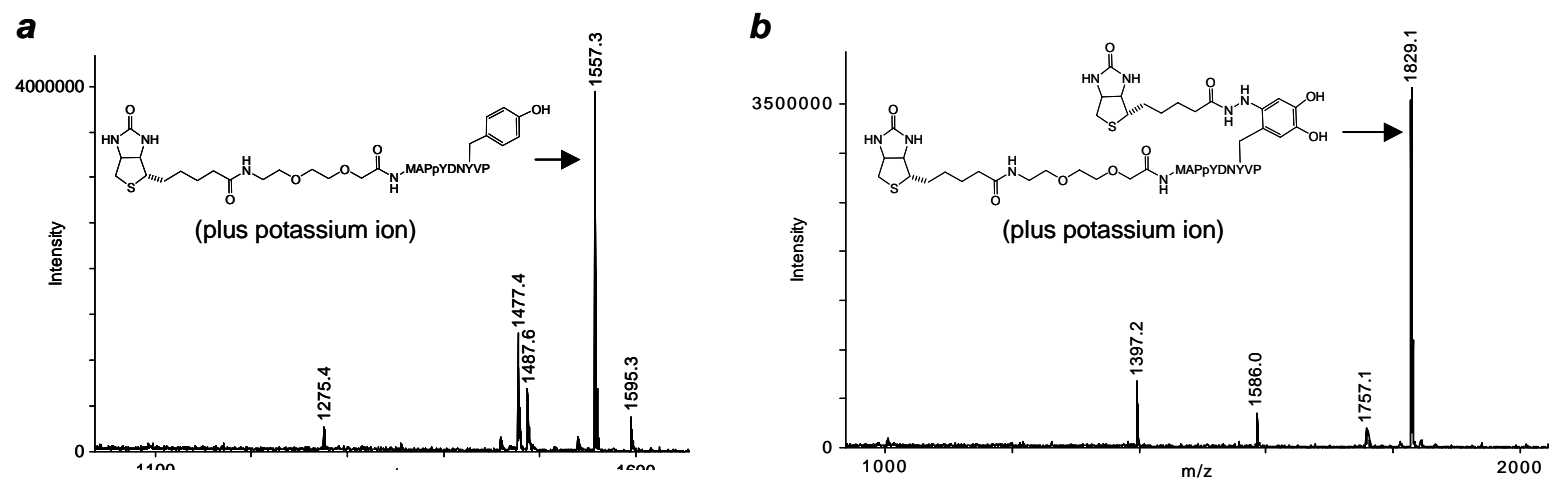

Figure S3. Mass spectrum of peptide biotin-miniPEG-MAPpYDNYVP before (panel $\boldsymbol{a}$ ) and after treatment with tyrosinase and biotin hydrazide (panel $\boldsymbol{b}$ ). 
$a$

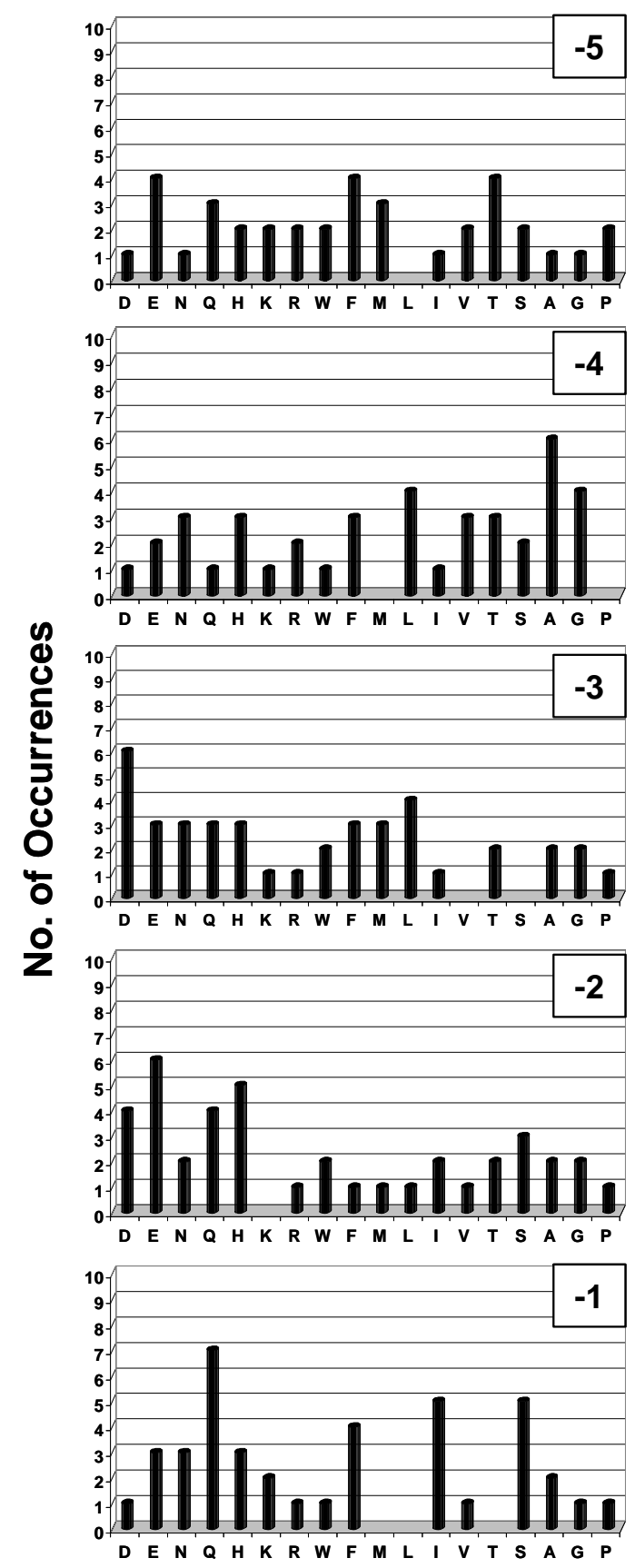

$\boldsymbol{b}$
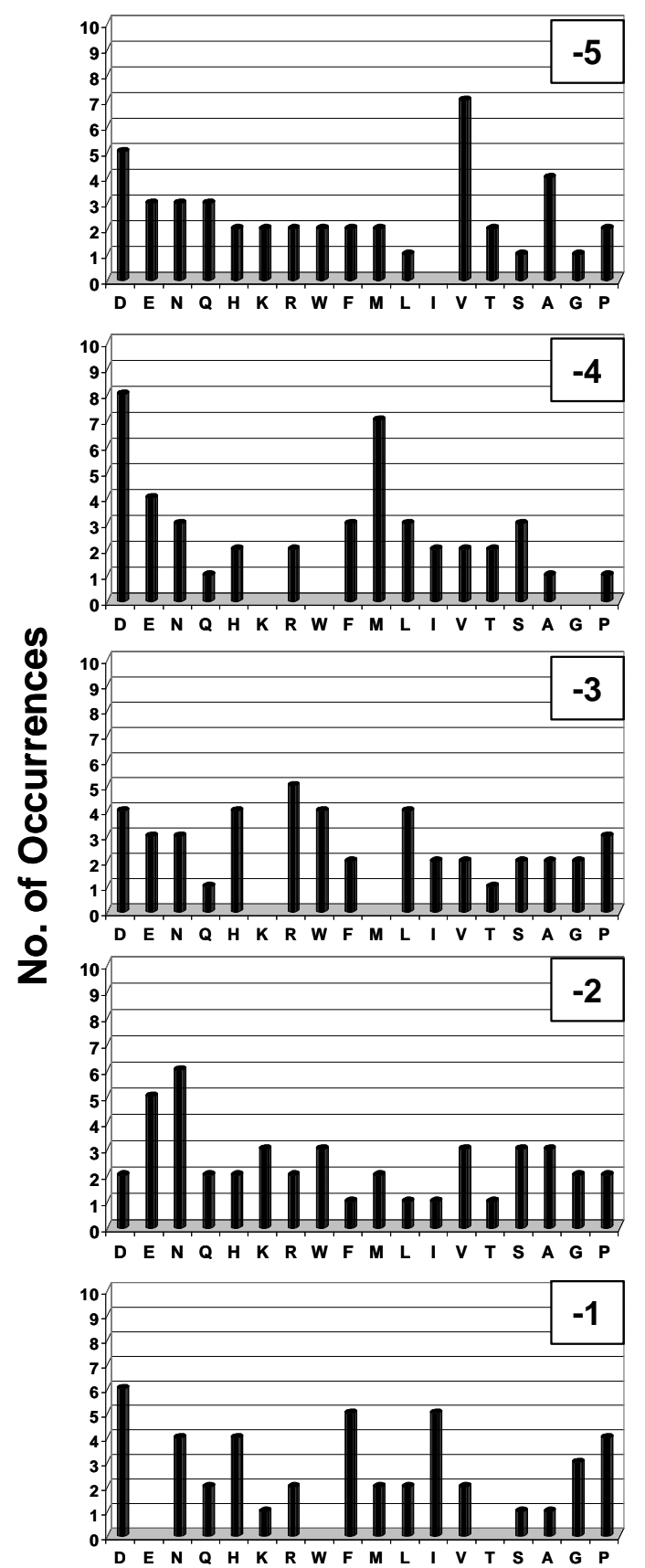

Figure S4. Less preferred PTP1B substrates derived from intermediately colored beads in Table S6 (panel $\boldsymbol{a}$ ) and lightly colored beads in Table S7 (panel $\boldsymbol{b}$ ). Displayed are the amino acids identified at each position from -5 to -1 relative to $\mathrm{pY}$ (position 0 ). Number of occurrences on the $\mathrm{y}$ axis represents the number of selected sequences that contain a particular amino acid at a certain position. M, norleucine. 


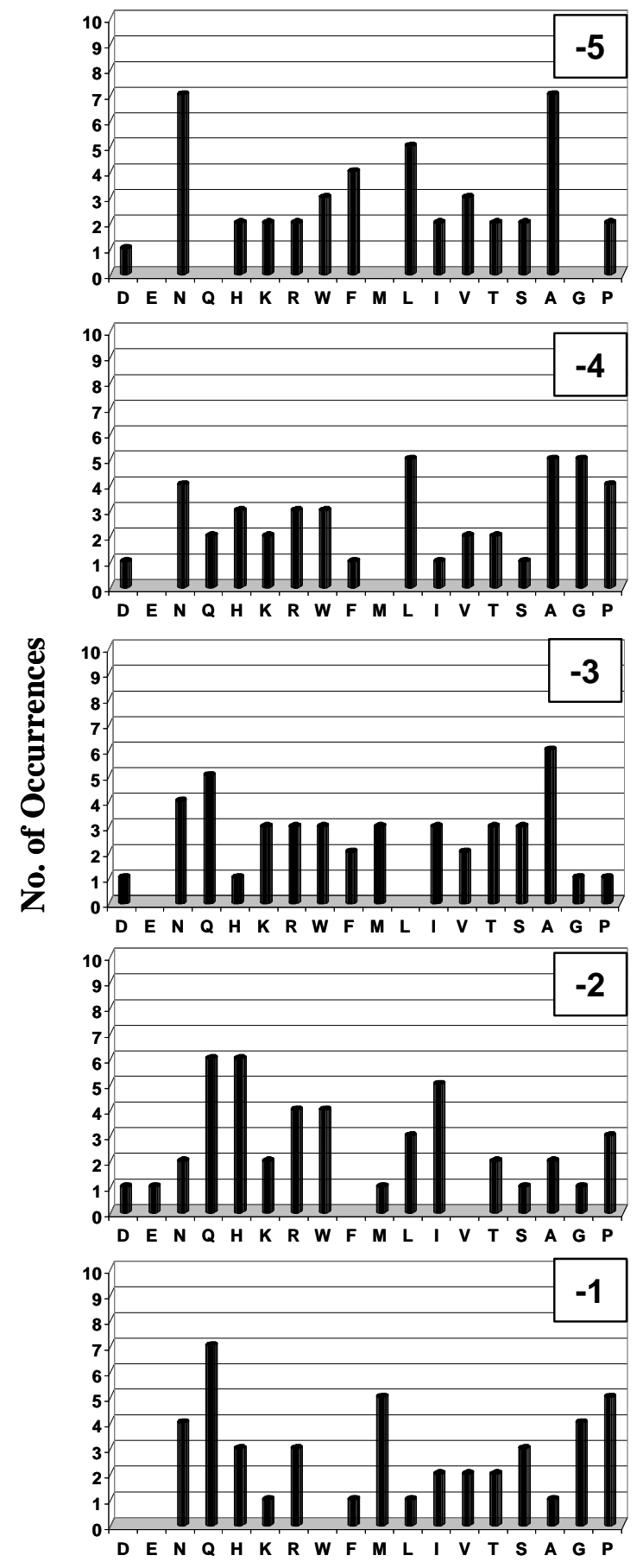

Figure S5. PTP1B-resistant peptides derived from the colorless beads (Table S8). Displayed are the amino acids identified at each position from -5 to -1 relative to $\mathrm{pY}$ (position 0 ). Number of occurrences on the $y$ axis represents the number of selected sequences that contain a particular amino acid at a certain position. $\mathrm{M}$, norleucine. 

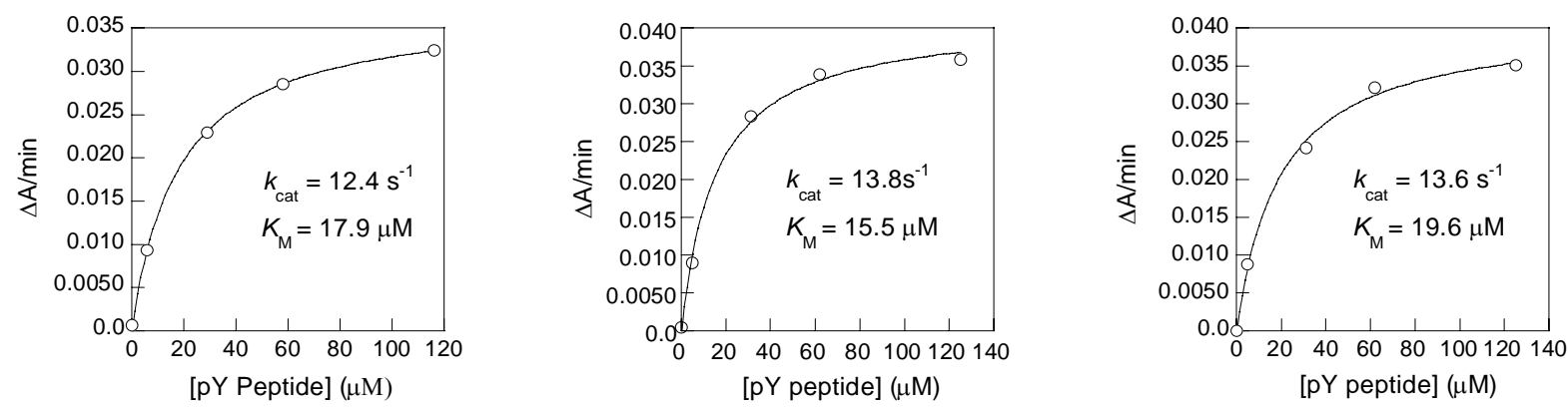

Figure S6. Velocity vs [S] plot for the dephosphorylation of peptide RTINEpYAA-NH $\mathrm{N}_{2}$ by PTP1B from three independent experiments (at $\mathrm{pH} 7.4$ ).

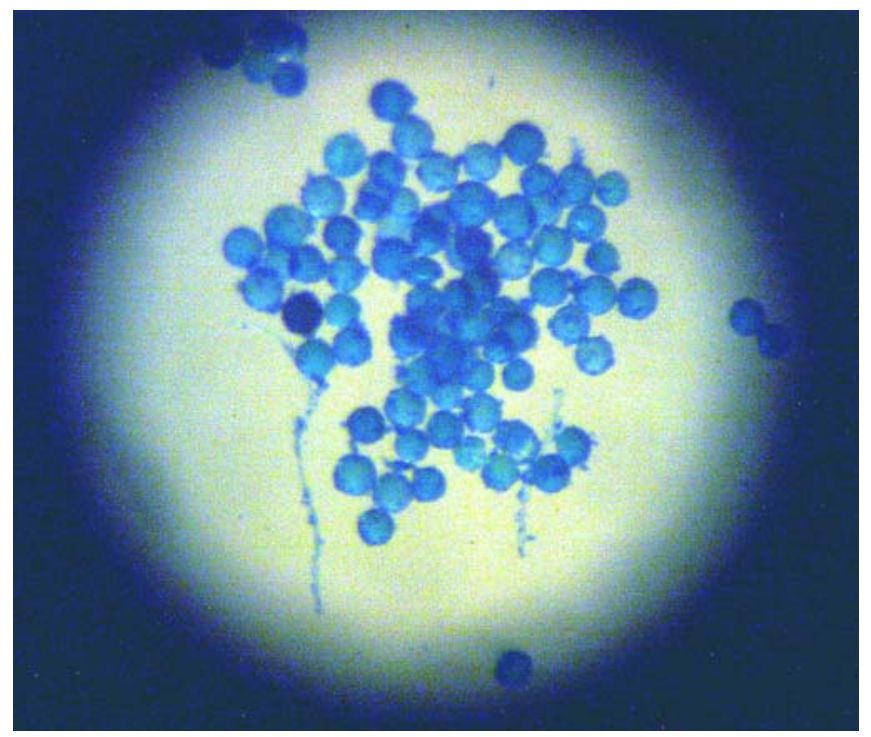

Figure S7. A photograph of a fraction of library $\mathrm{C}$ beads after treatment with tyrosinase, biotin hydrazide, SA-AP, and BCIP. 